\title{
Cold Climate Air Source Heat Pumps with Energy Storage: Evaluating the Impacts of a Carbon Reduction Strategy for New England
}

\author{
Bryan Urban ${ }^{1}$ and Kurt Roth ${ }^{1}$ \\ ${ }^{1}$ Fraunhofer USA, Boston, MA, USA
}

\begin{abstract}
Reaching an energy-efficient, low-carbon future means rethinking how we heat our buildings. Cold climate airsource heat pumps (ASHP), an attractive alternative to direct fossil fuel combustion, are being considered in Massachusetts and elsewhere to support strategic electrification policy. Shifting to ASHP heating could lower primary energy use and carbon emissions but may also impact customers' energy bills in complex ways. To evaluate potential tradeoffs, scenario-based simulations were applied to three commercial building types (Office, Retail, and School). Baseline fossil heating systems were replaced by efficient ASHP to evaluate impacts on energy consumption, peak load, and energy costs. Costs were evaluated under three demand-based electric rate structures. Finally, onsite battery storage was evaluated as an option for mitigating increased electric peaks. Results will inform ongoing policy discussions.
\end{abstract}

\section{Introduction}

Space heating in the U.S. - mostly on-site fossil fuel combustion, Figure 1 - accounts for over $20 \%$ of U.S. building-related primary energy consumption. Burning fuels directly to heat buildings, however, wastes highquality energy. Reaching an efficient, low-carbon future means rethinking how we heat our buildings.

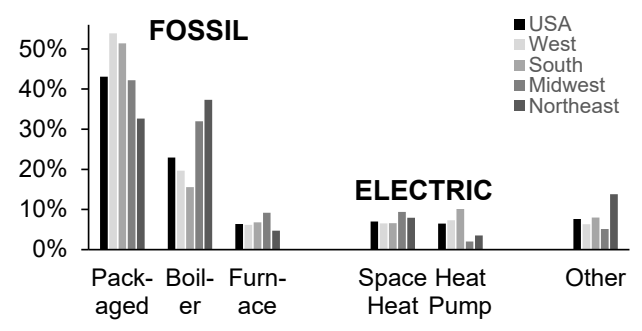

Figure 1. Heating type by region, percent of total heated commercial floor area (2012 CBECS, EIA 2015).

\section{Strategic Electrification}

Many local, regional, and global initiatives are exploring policies to support the transition to an efficient, costeffective, low-carbon energy future. The Commonwealth of Massachusetts (MA), for one, has aggressive

\footnotetext{
1 At peak conditions, combined-cycle gas plants can reach efficiencies above $60 \%$. This illustrative example excludes transmission and distribution losses, typically about $8 \%$ from plant to load.
}

greenhouse gas (GHG) reduction targets, foremost to achieve at least an 80 percent reduction in state-wide GHG emissions by 2050 .

To achieve these goals, analysts have found that most space-heating would need to be electrified and ultimately met by renewable power generation (NEEP 2017). Even with ideal conversion efficiency, conventional heating systems that burn fossil fuels cannot be carbon-neutral.

Prior studies have evaluated the ramifications of heating system electrification in California (Tarrojaa et al. 2018) and residential-sector electrification in different regions (Billomoria et al. 2018). Operating cost impacts for the commercial building sector, however, have received less attention and are less well understood.

This paper considers air source heat pumps (ASHP), an electric space heating technology with a long track record. Although ASHP have gained traction in the MA residential HVAC market, their adoption in commercial buildings has been limited due to concerns about operating costs, particularly in regions with high electric demand charges.

\section{Cold Climate Air Source Heat Pumps}

About two-thirds of the total U.S. commercial building space heating energy consumption occurs in cold and very cold climates $\left(\mathrm{HDD}_{18^{\circ} \mathrm{C}}>3000 ; \mathrm{HDD}_{65^{\circ} \mathrm{F}}>5400\right)$. Cold climate ASHP, designed to maintain capacity and efficiency at low outdoor temperatures, can yield seasonal coefficients of performance (COP, heat out per unit electricity in) that approach or exceed three.

Briefly, the logic of using ASHP heating can be illustrated with a simple natural gas example. The average thermal efficiency of a modern natural gas-fired electric power plant is about $44 \% .{ }^{1}$ Using electricity from this source, an efficient cold climate ASHP with a seasonal heating COP of three would yield about $0.44 \times 3=1.3$ units of heat per unit of fuel. In contrast, the best available gas furnace could deliver at most about 0.95 units of heat burning the same fuel on site. Put another way, in this example, burning fossil fuels directly for heat would require about 1.4 times more primary energy than first generating electricity and then running an efficient ASHP. ${ }^{2}$

\footnotetext{
2 The average U.S. primary energy conversion efficiency for electricity production - about $33 \%$ in 2012 (EIA 2016) - was somewhat lower than the previous example. Even so, a seasonal average heating $\mathrm{COP}$ of three would still slightly outperform onsite combustion from an energy standpoint.
} 
ASHP performance can vary significantly and depends on equipment, loading conditions, system design, and critically, outdoor temperature. Real-world performance data, especially for large commercial equipment, are sparse, as cold climate heat pumps have yet to achieve widespread U.S. market share. Consequently, this analysis uses simplified performance models based on the limited available data for larger residential-based systems.

\section{Research Questions}

Energy performance and carbon reductions are only part of the story. Even if the energy and carbon reductions prove viable, customers may face unfavorable billing impacts related to substantially higher facility electric peak demand charges.

In many places, peak demand charges are driven by summertime cooling loads. In a future with widespread electrified heating, winter peak loads - both at building and grid scales - would increase substantially and may exceed summer peaks (NEEP 2017). This would result in higher monthly electric demand charges, and potentially, new rate structures with significant cost implications.

Battery storage systems, deployed in conjunction with ASHP, could play an important role in managing both new and existing electric peaks.

This study, therefore, set out to examine the first-order energy, carbon, and energy-cost tradeoffs that come with switching from conventional natural gas (or oil) heating to ASHP. The analysis considers the energy, cost, and carbon consequences of switching from conventional heating systems to ASHP heating.

This modeling exercise was designed to show how ASHP systems, both with and without and battery storage, compare with conventional on-site fossil-fuel combustion heating systems in terms of:

1. Primary energy consumption

2. Energy costs

3. Carbon intensity

as a function of building type, energy and demand rates, and carbon intensity of the electric grid.

\section{Methods}

The effects of switching from fossil fuel heating to electric ASHP were estimated as follows:

1. Select building types and climate

2. Model baseline building

3. Develop ASHP performance model

4. Develop battery storage model

5. Model energy costs

6. Model carbon impacts

\section{Building Models}

Three prototypical commercial building models - Office, Retail, and School, Table 1 - were selected in consultation with the project sponsor to represent a range of electric and heating load profiles and demand magnitudes. These building types were selected because they represent a large fraction of the total MA commercial-sector energy use and because they are likely candidates for ASHP retrofits based on initial market traction.
Modeling was performed using EnergyPlus (v8.9) using prototypical building models (2004 new construction vintage) to represent a somewhat average baseline energy performance case for existing buildings. Detailed model characteristics and input files are available online (DOE 2012, prototypical model v.1.4_7.2, Climate Zone 5A).

Table 1. Baseline building summary.

\begin{tabular}{|c|c|c|c|}
\hline Characteristic & $\begin{array}{c}\text { Medium } \\
\text { Office }\end{array}$ & $\begin{array}{c}\text { Big-box } \\
\text { Retail }\end{array}$ & $\begin{array}{c}\text { Secondary } \\
\text { School }\end{array}$ \\
\hline Floor Area $(000) \mathrm{m}^{2}$ & 5.0 & 2.3 & 19.6 \\
\hline Floors & 3 & 1 & 1 \\
\hline Zones & 15 & 5 & 46 \\
\hline Heating System & Furnace & Furnace & Boiler \\
\hline Fuel & Nat. Gas & Nat. Gas & Nat. Gas \\
\hline Efficiency & $80 \%$ & $80 \%$ & $78 \%$ \\
\hline Setpoint ${ }^{\circ} \mathrm{C}\left({ }^{\circ} \mathrm{F}\right)$ & $21(70)$ & $21(70)$ & $21(70)$ \\
\hline \multicolumn{4}{|c|}{$\begin{array}{l}\text { Note: ASHP replacements were considered for heating systems } \\
\text { only. Baseline cooling systems included packaged, unitary, and } \\
\text { chiller, with nominal COP ranging from } 2.8 \text { to } 3.7 \text {. }\end{array}$} \\
\hline
\end{tabular}

The raw models were were adjusted in two ways prior to simulation. First, timesteps were changed to $15 \mathrm{~min}$. to generate finer resolution loads for demand analysis. Second, all nighttime thermostat temperature setbacks were disabled. Using night setbacks with heat pumps can yield an intense morning recovery period that would require larger capacity equipment. Night setbacks could also produce more inefficient cold temperature operation and/or higher reliance on auxiliary heat, and potentially increase facility peak demand during recovery. Eliminating setbacks in the baseline avoids these issues while maintaining a consistent basis for comparison. Nighttime ventilation setback schedules, however, were kept as-is, reducing nighttime heating demand in all cases.

\section{Climate Data}

New England states including Massachusetts, belong to the cold $\left(3000-5000 \mathrm{HDD}_{18^{\circ} \mathrm{C}} ; 5400-9000 \mathrm{HDD}_{\left.65^{\circ} \mathrm{F}\right)}\right.$ and very cold $\left(5000-7000 \mathrm{HDD}_{18^{\circ} \mathrm{C}} ; 9000-12600 \mathrm{HDD}_{65^{\circ} \mathrm{F}}\right)$ climate regions. These regions account for about twothirds of the total U.S. commercial space heating energy consumption. Hourly TMY3 weather data for Boston, MA $\left(447 \mathrm{CDD}_{18^{\circ} \mathrm{C}}\left[804 \mathrm{CDD}_{65^{\circ} \mathrm{F}}\right]\right.$ and $3270 \mathrm{HDD}_{18^{\circ} \mathrm{C}}$ [5885 $\left.\left.\mathrm{HDD}_{65^{\circ} \mathrm{F}}\right]\right)$ were used for all simulations. Outdoor temperatures ranged from -20 to $37^{\circ} \mathrm{C}\left(-4\right.$ to $\left.99^{\circ} \mathrm{F}\right)$.

\section{Air-Source Heat Pump Model}

The ASHP heating coefficient of performance (COP), defined as heat output divided by electricity input, depends mainly on outdoor air temperature, and less so on part-load fraction. Colder temperatures reduce capacity and COP, dropping somewhat linearly from the rated condition and leveling out at colder temperatures. A second steep drop-off may occur at very cold temperatures (below about $-23^{\circ} \mathrm{C}\left[10^{\circ} \mathrm{F}\right]$; Schuetter and Hackel 2015). When this happens, supplemental auxiliary gas or electric resistance heat may be required.

Energy performance data for commercial cold climate ASHP were not readily available. Instead, we consulted a large performance database for residential cold climate ASHP equipment (NEEP 2018). This public database 
includes manufacturer-reported COP data measured at up to three temperatures $\left(-15,-8.3\right.$, and $\left.8.3^{\circ} \mathrm{C}\left[5,17,47^{\circ} \mathrm{F}\right]\right)$ and capacities (minimum, maximum, and rated) covering over 1200 different equipment models. Performance varied with load fraction, heat pump type (ducted vs. ductless), and outdoor temperature.

Since commercial units tend to be sized much larger than most residential units, we focused on the 78 equipment models with heating capacity $\geq 4$ tons ( $14 \mathrm{~kW}$-th, [48000 $\mathrm{Btu} / \mathrm{h}]$ ), Figure 2. Based on these high-efficiency units, we developed simple correlations for COP as a function of outdoor temperature $T(1)$ :

$$
C O P=A \cdot T^{2}+B \cdot T+\mathrm{C}
$$

where

$\begin{array}{lllc}A & B & C & \text { Units of } T \\ 0.00142 & 0.0784 & 3.05 & { }^{\circ} \mathrm{C} \\ 0.00044 & 0.0154 & 2.11 & { }^{\circ} \mathrm{F}\end{array}$

Note that these relationships are applicable only between about -20 to $+15^{\circ} \mathrm{C}\left(-5\right.$ to $\left.+60^{\circ} \mathrm{F}\right)$. At higher temperatures, performance eventually plateaus. At colder temperatures, performance and capacity could drop off sharply, and auxiliary heat could be required. This situation can be modelled by setting the COP to 1 for the portion of load met by electric-resistance heat. Auxiliary heat was not required for the climate data considered.

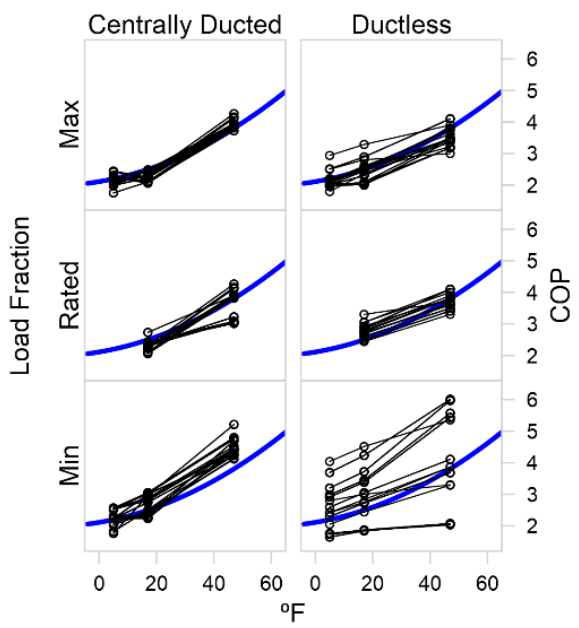

Figure 2. ASHP heating COP vs. outdoor temperature and load fraction. Based on NEEP (2018), units $\geq 4$ ton

(14 kW-th [48000 Btu/h]). Blue line from Eq. (1).

ASHP performance tends to improve at lower partloading. We considered modeling this effect using partload data from (NEEP 2018); however, this approach gave seasonal COP values that were much higher than those found in recent field tests - on the order of 4.5-4.7 vs. less than 3 (Korn et al. 2016). In light of this discrepancy, we ultimately based the COP analysis on maximum capacity performance.

To apply the ASHP models, we estimated the total building heating loads from the baseline simulation's gas heating consumption and heating system efficiency (typ. $80 \%$ ). Next, we sized the ASHP system to meet the maximum heating load and applied the COP model to estimate the 15-minute ASHP electric loads for the entire year. Adding the ASHP loads to the building electric loads gives the new building electric load profile.

Secondary advantages of ASHP were not modeled. Variable refrigerant volume/flow systems, for instance, could reduce the need for simultaneous heating and cooling by allowing improved zoning and refrigerant distribution. Fan energy could also be reduced relative to air-based systems, as it takes less energy to circulate refrigerants compared with large volumes of air. Such details are building- and case-specific and were therefore not included in this top-level analysis. Both factors would tend to improve the favorability of ASHP systems.

While more sophisticated and potentially more accurate approaches exist for modeling ASHP performance, these are more appropriate for specific building design simulation. The inherent variability in performance among different equipment models, for instance, would tend to outweigh any potential accuracy improvements.

\section{Battery Energy Storage System Model}

Since switching to electric ASHP heating tends to increase facility peaks loads during heating months, an onsite energy storage system (ESS) was evaluated for its potential to mitigate peak loads using the following idealized modeling assumptions:

1. Storage capacity is sized to meet half the facility annual peak load (15-min.) for four hours.

2. Roundtrip energy conversion efficiency is $85 \%$.

3. ESS controls minimize monthly on-peak demand (ideal case, perfect knowledge).

4. The battery recharges completely once per day during off-peak hours only.

For each building, the ESS model was applied to the simulated loads for the entire year (8760 hours), yielding a new 15-minute electric load profile with lower monthly peaks and slightly higher total electricity consumption.

Peak demand reduction potentials depend on ESS capacity relative to building peak load. We sized the ESS for $50 \%$ of the 15 -minute peak demand for all three building types and assumed a four-hour battery capacity (MassCEC and Mass DOER 2016). That is, a facility with a 15-min. peak demand of $400 \mathrm{~kW}$ would size the ESS for $200 \mathrm{~kW}$ and $800 \mathrm{kWh}$.

To control the ESS, we first assessed each day of the year to find the lowest possible on-peak load by discharging the battery fully during the peak-demand period. Next, for each month, we found the limiting day - that with the highest peak after the optimal battery strategy has been applied. Finally, this new limiting peak was used as the new demand threshold to which all days in the month are controlled. This strategy maximizes peak reduction, while minimizing reliance on the battery, therefore avoiding unnecessary costs and penalties associated with charging and discharging losses.

\section{Energy Cost}

Three electricity pricing scenarios - designed to represent low, medium, and high monthly demand charges $(\$ 10$, 
$\$ 20$, and $\$ 40 / \mathrm{kWp}$ - were chosen to represent the range of conditions in MA for 2018. While actual on-peak times vary by provider, and in some cases by season, we modeled on-peak hours as 8 A.M. to 9 P.M. on weekdays.

Energy consumption components were modeled using fixed, representative prices - $\$ 100 / \mathrm{MWh}$ for electricity and \$1/therm for natural gas (EIA 2018).

Effective electricity prices in $\$ / \mathrm{MWh}$ resulting from this analysis ranged from 66-91 (Low rate), 131-182 (Med), and 163-265 (High). For comparison, MA, at 159, had the fourth highest average commercial retail electricity price in the U.S. - about 50\% higher than the national average of \$107/MWh (for 2017, EIA 2019).

Many regions, including MA, offer competitive energy supply, giving commercial customers access to a range of supply rates, some with variable time-of year pricing. Other, more complex rate structures could be evaluated readily using the simulated energy and peak data.

\section{Carbon Intensity}

To achieve significant GHG reductions through space heat electrification, the $\mathrm{CO}_{2}$ intensity of the electric grid must be favorably low relative to space heating fuels. Approximate emissions ( $\left.\mathrm{kg} \mathrm{CO}_{2} / \mathrm{MWh}\right)$ associated with directly burning fuels for heat are 175 for natural gas, 252 for oil, and 318 for coal (EIA 2016). Electric emission intensities vary more strongly among and within countries and change over time, Figure 3.

From 2001 to 2017 , the average $\mathrm{CO}_{2}$ intensity of the U.S. grid fell by $30 \%$, driven due to increased natural gas and wind production, with the largest reductions (58\%) occurring in the Northeast (Schivley et al. 2018). If this trend continues, electrified space heating would become even more effective at reducing carbon emissions.

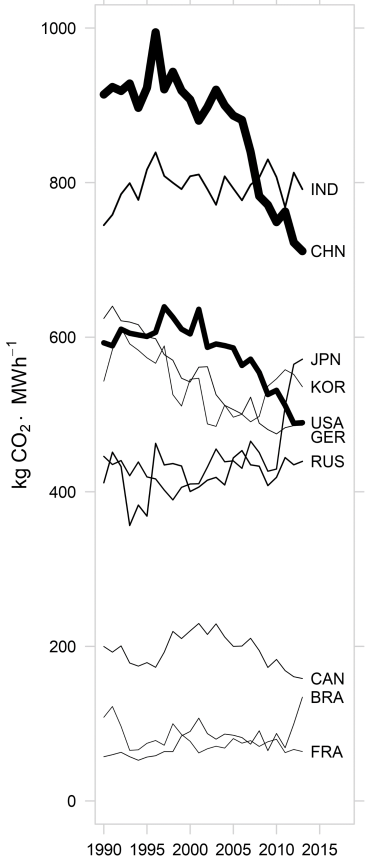

Line weights proportional to total electricity production. Based on OECD (2015).

Figure 3. Grid CO2 intensity of the ten highest electricity-producing countries.

\section{Results}

\section{Energy Impact}

Simulated load profiles for peak winter and summer weeks, Figure 4, show the main effects of ASHP heating and battery storage. Electric loads increased most significantly during occupied hours, when ventilation contributed most to heating loads.

Winter electric peaks increased greatly with ASHP heating, more than doubling for the retail and school buildings. Annual site electricity consumption also increased by 13, 26, and 28 percent for the Office, Retail, and School, respectively. Summer peaks stayed the same with ASHP, since we did not model cooling system replacement. Adding ESS, however, did significantly reduce the summer peaks.

Battery storage, sized to meet half the peak annual load for four hours, was able to mitigate most of the new peak in the Office, but only part for Retail and School. The storage system also increased annual electricity consumption, but only marginally (about $2 \%$ ), due to roundtrip conversion losses.
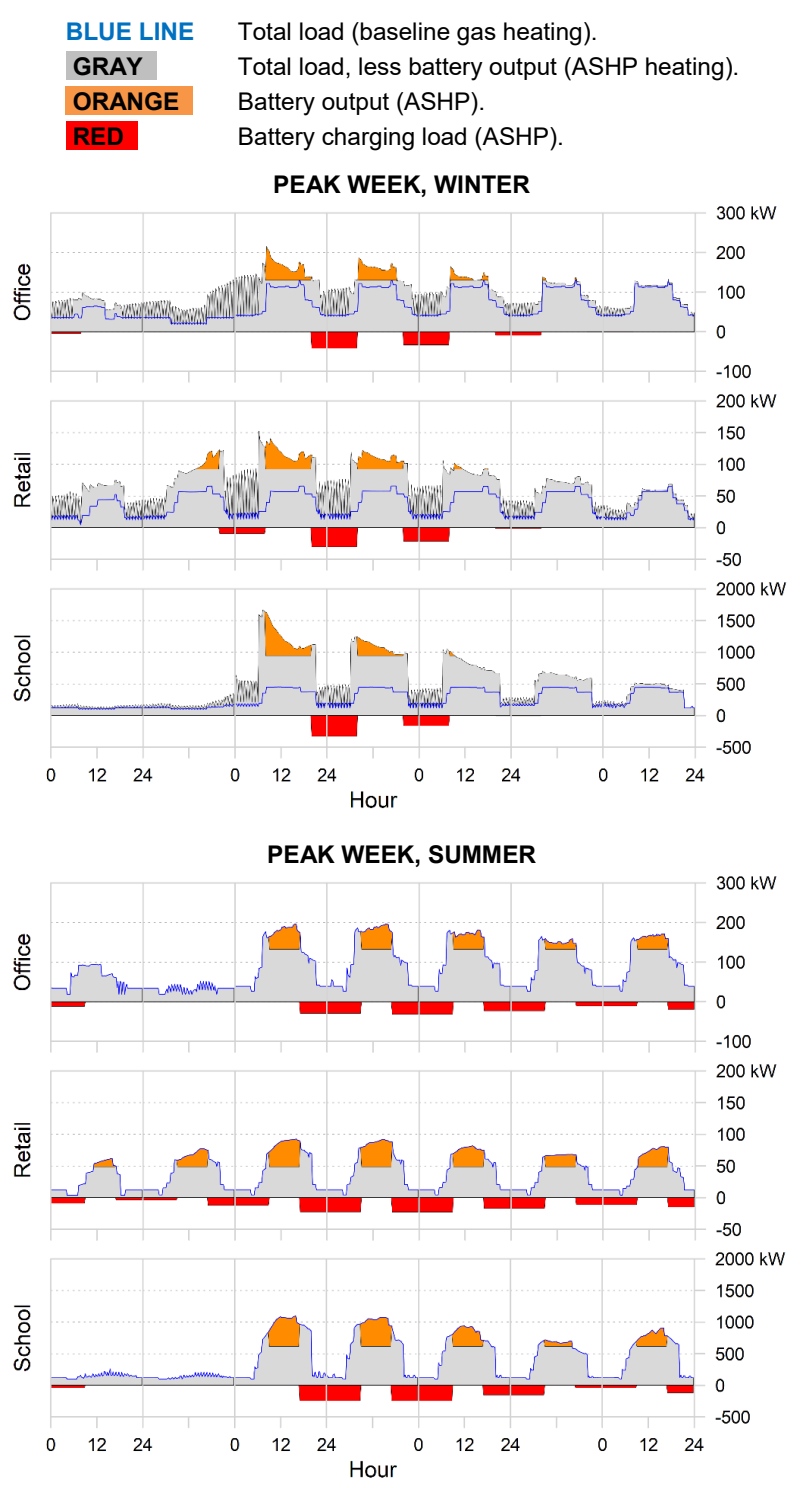

Figure 4. Electric load profiles for peak weeks. 
Table 2. Simulated electric and gas consumption.

$B L=$ Baseline, $H P=$ Heat Pump, $E S=H P+$ Energy Storage

\begin{tabular}{|c|c|c|c|c|c|c|c|c|c|}
\hline \multicolumn{10}{|c|}{ Office $\left(5000 \mathrm{~m}^{2}\right)$} \\
\hline & \multicolumn{3}{|c|}{ Peak (kW) } & \multicolumn{3}{|c|}{ Use (MWh-e) } & \multicolumn{3}{|c|}{ Gas (MWh-th) } \\
\hline & BL & HP & ES & BL & HP & ES & BL & HP & $\mathbf{E S}$ \\
\hline Jan & 129 & 216 & 130 & 48 & 70 & 70 & 76 & 1 & 1 \\
\hline Feb & 129 & 178 & 105 & 43 & 58 & 59 & 56 & 1 & 1 \\
\hline Mar & 141 & 149 & 86 & 49 & 60 & 61 & 43 & 1 & 1 \\
\hline Apr & 162 & 162 & 103 & 45 & 51 & 51 & 25 & 1 & 1 \\
\hline May & 165 & 165 & 108 & 50 & 51 & 52 & 7 & 1 & 1 \\
\hline Jun & 197 & 197 & 132 & 55 & 55 & 56 & 2 & 1 & 1 \\
\hline Jul & 197 & 197 & 135 & 61 & 61 & 62 & 1 & 1 & 1 \\
\hline Aug & 196 & 196 & 129 & 63 & 63 & 64 & 1 & 1 & 1 \\
\hline Sep & 177 & 177 & 112 & 53 & 53 & 54 & 1 & 1 & 1 \\
\hline Oct & 148 & 148 & 95 & 49 & 51 & 52 & 14 & 1 & 1 \\
\hline Nov & 141 & 172 & 108 & 47 & 56 & 56 & 37 & 1 & 1 \\
\hline Dec & 129 & 170 & 102 & 47 & 61 & 62 & 56 & 1 & 1 \\
\hline Max. & 197 & 216 & 135 & - & - & - & - & - & - \\
\hline Sum. & - & - & - & 609 & 690 & 699 & 320 & 10 & 10 \\
\hline \multicolumn{10}{|c|}{ Retail (2 $\left.300 \mathrm{~m}^{2}\right)$} \\
\hline & \multicolumn{3}{|c|}{ Peak $(k W)$} & \multicolumn{3}{|c|}{ Use (MWh-e) } & \multicolumn{3}{|c|}{ Gas (MWh-th) } \\
\hline & BL & HP & ES & BL & HP & ES & BL & HP & ES \\
\hline Jan & 66 & 141 & 92 & 27 & 49 & 49 & 76 & 0 & 0 \\
\hline Feb & 65 & 112 & 70 & 24 & 39 & 40 & 58 & 0 & 0 \\
\hline Mar & 65 & 90 & 53 & 26 & 37 & 38 & 46 & 0 & 0 \\
\hline Apr & 77 & 81 & 44 & 24 & 30 & 31 & 27 & 0 & 0 \\
\hline May & 78 & 78 & 39 & 25 & 26 & 27 & 8 & 0 & 0 \\
\hline Jun & 93 & 93 & 49 & 26 & 26 & 27 & 1 & 0 & 0 \\
\hline Jul & 94 & 94 & 58 & 30 & 30 & 30 & 0 & 0 & 0 \\
\hline Aug & 93 & 93 & 49 & 29 & 29 & 30 & 0 & 0 & 0 \\
\hline Sep & 83 & 83 & 38 & 25 & 25 & 26 & 1 & 0 & 0 \\
\hline Oct & 65 & 74 & 39 & 26 & 28 & 29 & 14 & 0 & 0 \\
\hline Nov & 65 & 105 & 67 & 25 & 34 & 34 & 36 & 0 & 0 \\
\hline Dec & 66 & 106 & 64 & 26 & 40 & 41 & 54 & 0 & 0 \\
\hline Max. & 94 & 141 & 92 & - & - & - & - & - & - \\
\hline Sum. & - & - & - & 313 & 395 & 403 & 321 & $\mathbf{0}$ & $\mathbf{0}$ \\
\hline \multicolumn{10}{|c|}{ School $\left(19600 \mathrm{~m}^{2}\right)$} \\
\hline & \multicolumn{3}{|c|}{ Peak (kW) } & \multicolumn{3}{|c|}{ Use (MWh-e) } & \multicolumn{3}{|c|}{ Gas (MWh-th) } \\
\hline & BL & HP & ES & BL & HP & ES & BL & HP & $\mathbf{E S}$ \\
\hline Jan & 453 & 1631 & 944 & 186 & 368 & 369 & 624 & 23 & 23 \\
\hline Feb & 453 & 1225 & 701 & 167 & 291 & 295 & 469 & 21 & 21 \\
\hline Mar & 615 & 903 & 437 & 194 & 276 & 284 & 360 & 25 & 25 \\
\hline Apr & 867 & 867 & 454 & 177 & 215 & 219 & 189 & 21 & 21 \\
\hline May & 805 & 805 & 404 & 195 & 208 & 212 & 82 & 22 & 22 \\
\hline Jun & 1097 & 1097 & 617 & 231 & 235 & 238 & 38 & 18 & 18 \\
\hline Jul & 862 & 862 & 355 & 189 & 189 & 194 & 10 & 10 & 10 \\
\hline Aug & 869 & 869 & 355 & 189 & 189 & 195 & 12 & 11 & 11 \\
\hline Sep & 911 & 911 & 422 & 205 & 207 & 213 & 26 & 16 & 16 \\
\hline Oct & 682 & 682 & 299 & 183 & 206 & 212 & 129 & 20 & 20 \\
\hline Nov & 495 & 1077 & 619 & 180 & 245 & 249 & 283 & 21 & 21 \\
\hline Dec & 462 & 1057 & 553 & 181 & 285 & 291 & 422 & 21 & 21 \\
\hline Max. & 1097 & 1631 & 944 & - & - & - & - & - & - \\
\hline Sum. & - & - & - & 2278 & 2914 & 2970 & 2646 & 229 & 229 \\
\hline
\end{tabular}

\footnotetext{
${ }^{3}$ Demand was based on the max. 15 -minute power draw on weekdays (9AM-6PM Jun-Sept., 8AM-9PM Oct-May.)
}

Monthly and annual values for on-site gas and electricity consumption and demand, ${ }^{3}$ Table 2 and Figure 5, describe the impacts of the different heating concepts.

Optimal battery storage was able mitigate much of the increased winter demand with a relatively minor energy penalty. In addition, battery storage had considerable year-round benefits, reducing peak loads and associated costs during all months.

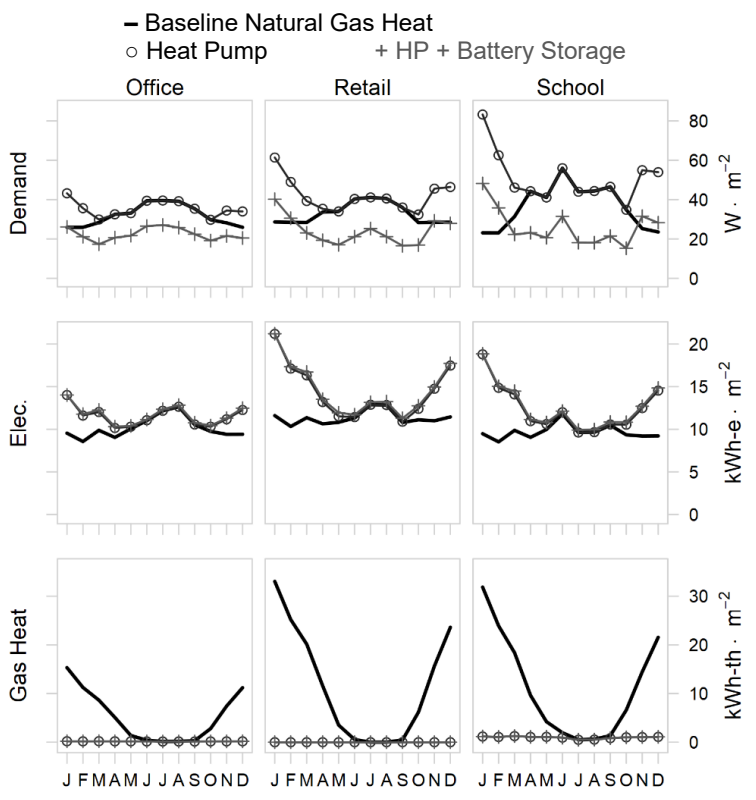

Figure 5. Simulated monthly peak electric demand, electricity and gas consumption per floor area.

\section{Carbon Dioxide Emissions}

The amount of $\mathrm{CO}_{2}$ emissions that could be avoided by switching from direct fossil fuel heating to electric heating depends on the carbon intensity of the grid and on the fuels used for on-site heating. Since these values can vary strongly by region and over time, as in Figure 3, we present results first for the specific MA example, Table 3, and then in more general terms.

Natural gas heating in the baseline (for Office, Retail, and School, respectively) represented 34,51 , and 54 percent of total site energy use, and 19, 32, and 35 percent of total building carbon emissions.

Switching to ASHP led to carbon reductions of about $44 \%$ of baseline heating-related emissions based on the carbon intensity of today's MA grid. Adding energy storage gives slightly lower carbon reductions - about $37-39 \%$ - due to roundtrip efficiency losses.

For current U.S. grid and natural gas heating fuel values, heating-related $\mathrm{CO}_{2}$ reductions were somewhat lower, at $29-31 \%$ (22-24\% with storage). Fuel oil heating, which produces about $252 \mathrm{~kg} \mathrm{CO}_{2} / \mathrm{MWh}$-th, yields more favorable heating reductions (up to $64 \%$ in the MA case).

Gas consumption is shown in $\mathrm{kWh}$-thermal to facilitate comparisons $(1$ therm $=29.3 \mathrm{kWh}$-th $)$. 
To extend these results more generally, we define the electric grid-to-heating-fuel $\mathrm{CO}_{2}$ intensity ratio, $R$, as

$$
R_{\mathrm{CO} 2}=I_{\text {electric-grid }} / I_{\text {heating-fuel }}
$$

where $I_{\text {electric-grid }}$ is the grid's intensity $\left(\mathrm{kg}-\mathrm{CO}^{2} / \mathrm{MWh}\right)$ and $I_{\text {heating-fuel }}$ is that of the baseline heating fuel.

The average $\mathrm{CO}_{2}$ intensity of the U.S. electric grid was $473 \mathrm{~kg} / \mathrm{MWh}$-e. Natural gas, meanwhile, had an average intensity of $175 \mathrm{~kg} / \mathrm{MWh}$-th (EIA 2018). These values yield an intensity ratio $R_{C O 2}=473 / 175=2.7$. Similarly, for $\mathrm{MA}, R_{\mathrm{CO} 2}=339 / 156=2.2$. Likewise, a $100 \%$ renewable electric grid would yield $R_{\mathrm{CO} 2}=0$. This ratio makes it possible to evaluate $\mathrm{CO}_{2}$ reductions under alternate or hypothetical grid and heating fuel scenarios. ${ }^{4}$ As a function of $R_{\mathrm{CO} 2}$, percent reductions in space heating were similar for the three buildings considered, Figure 6 , with energy storage resulting in slightly lower GHG reductions. For the cases we considered, the $\mathrm{CO}_{2}$ breakeven points occurred when $R_{\mathrm{CO} 2}$ was approximately 3.5 for the ASHP system and 3.8 for the ASHP with battery storage.

In reality, the situation is more nuanced, since the electric grid $\mathrm{CO}_{2}$ intensity varies as a function of time of year and time of day. On-peak consumption currently tends to be more intensive, and future grid intensities are likely to change over time. Higher renewable adoption, for instance, would tend to reduce intensities. Scenario-based analysis based on expected intensities and renewable production could be applied to annual load profiles to evaluate such tradeoffs.

\section{Percent Reduction in Space-Heating $\mathrm{CO}_{2}$ Emmisions}

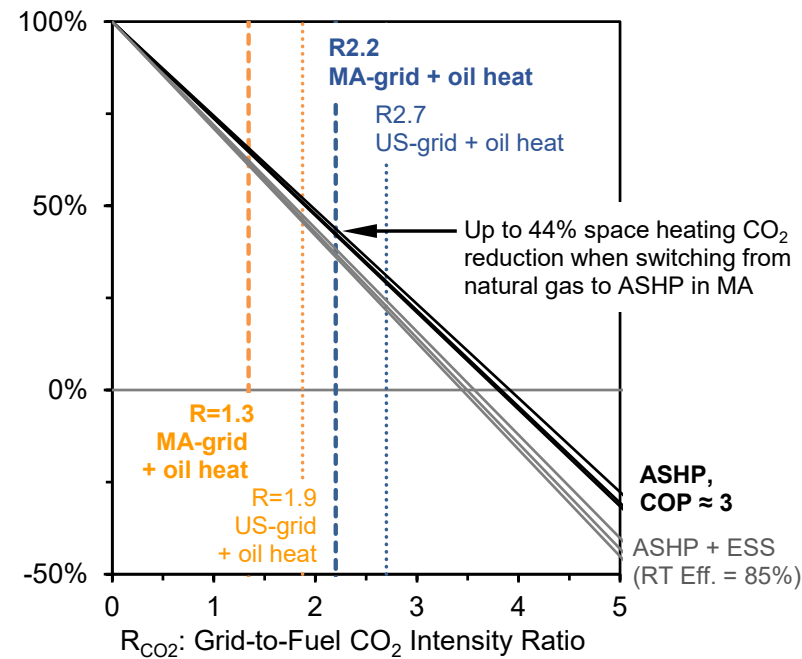

Figure 6. Percent reduction in space-heating-related $\mathrm{CO}_{2}$ emissions achieved by switching to ASHP vs. electric-grid-to-heating-fuel $\mathrm{CO}_{2}$ intensity ratio:

$$
R_{\mathrm{CO} 2}=I_{\text {electric-grid }} / I_{\text {heating-fuel. }}
$$

Table 3. Annual $\mathrm{CO}_{2}$ emissions and reductions,

\begin{tabular}{|c|c|c|c|c|c|c|}
\hline & \multicolumn{3}{|c|}{ Site (MWh) } & \multicolumn{2}{|c|}{$\left.(\mathrm{mt} \mathrm{CO})_{2}\right)$} & $\Delta(\mathbf{x}-\mathbf{B L})$ \\
\hline Offic & Elec. & Gas & TOT & Elec. & Gas TOT & Abs. \\
\hline Baseline & 609 & 320 & 929 & 206 & $50 \quad 256$ & \\
\hline & 690 & 10 & 700 & 234 & 2235 & -218 \\
\hline $\mathrm{HP}+$ & 699 & 10 & 709 & 237 & $\begin{array}{ll}2 & \mathbf{2 3 9}\end{array}$ & -187 \\
\hline Retail & & & & & & \\
\hline Base & 313 & 321 & 634 & 106 & $\begin{array}{|ll|}50 & \mathbf{1 5 6} \\
\end{array}$ & - \\
\hline & 95 & 0 & 395 & 134 & $\begin{array}{ll}0 & 134\end{array}$ & -2214 \\
\hline & 403 & 0 & 403 & 137 & $\begin{array}{ll}0 & 137\end{array}$ & -2012 \\
\hline Scho & & & & & & \\
\hline & 2278 & 2646 & 4924 & 772 & 4121184 & 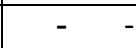 \\
\hline & 2914 & 229 & 3143 & 988 & $36 \mathbf{1 0 2 4}$ & \begin{tabular}{|ll}
-161 & 14
\end{tabular} \\
\hline$P+$ & 2970 & 229 & 3199 & 1007 & $36 \mathbf{1 0 4 3}$ & \begin{tabular}{|ll}
-142 & 12 \\
\end{tabular} \\
\hline & $\begin{array}{l}\text { Elec. } \\
\text { Nat. }\end{array}$ & & & $\mathrm{CO}$ & Wh-th & \\
\hline
\end{tabular}
based on Massachusetts emissions factors.

\section{Cost Impact}

Energy cost tradeoffs are shown for three electric rate scenarios in Table 4 and Figure 7. Baseline heating energy costs of $\$ 2.2-4.8 / \mathrm{m}^{2}$ accounted for $7-31$ percent of total facility energy consumption, depending on building type (retail and school similar, about twice that of office) and electric rate structure.

Switching to heat pumps increased the total site energy consumption by up to 18 percent for the medium and high rate structures $(2-10 \%$ at $\$ 20 / \mathrm{kWp}$ and $4-18 \%$ at $\$ 40 / \mathrm{kWp})$. For the low rate $(\$ 10 / \mathrm{kWp})$, however, savings of $6-12 \%$ were observed for all buildings. Cheaper electricity and more expensive heating fuels tend to make space heat electrification more financially attractive.
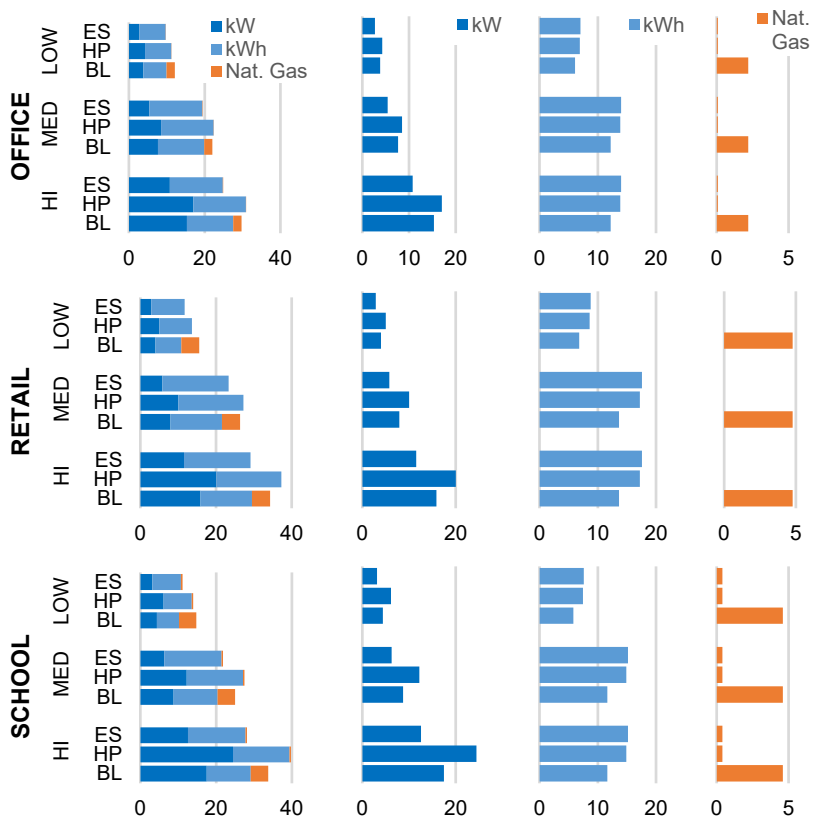

Figure 7. Energy costs per floor area $\left(\$ / \mathrm{m}^{2}\right)$.

\footnotetext{
${ }^{4}$ In all baseline (fossil-fuel heating) examples, we assumed an $80 \%$ fuel-to-heat conversion efficiency. Values could likewise be adjusted based on efficiency ratios.
} 
Table 4. Whole building annual energy cost components in $\$(000)$ by scenario.

$B L=$ Baseline, $H P=$ Heat Pump,$E S=H P+$ Energy Storage

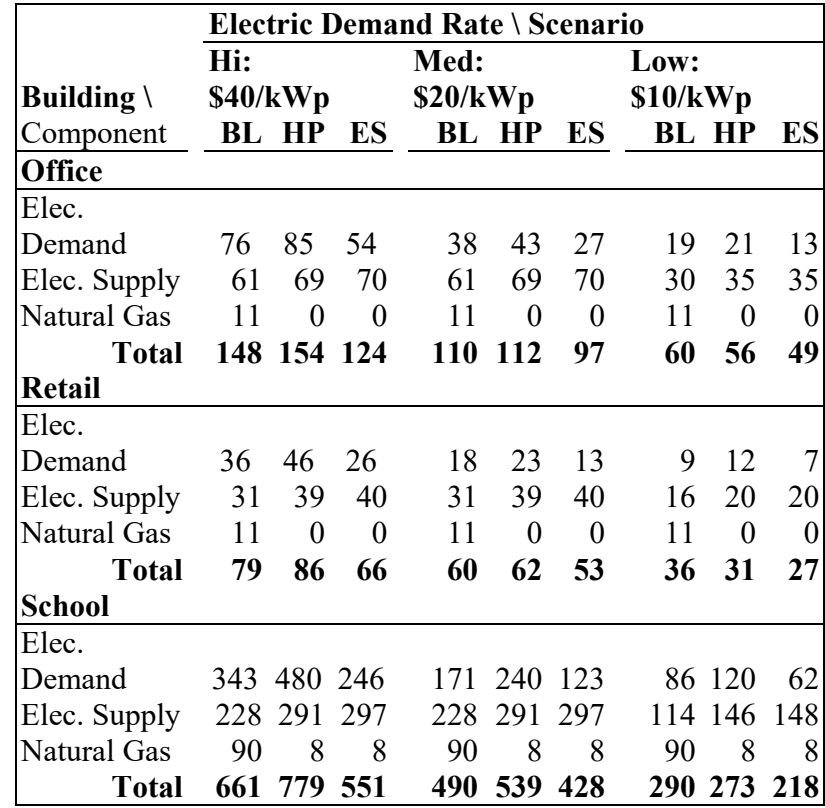

Adding a large battery energy storage system led to significant energy cost savings in all three scenarios, with the highest benefits in the high demand scenario. Lifecycle cost-effectiveness depends strongly on installed costs, which for battery storage system can vary widely. Installed costs for long-duration ESS like those considered here currently range from about \$1500-4000 per MW or $\$ 300-800$ per $\mathrm{kWh}$ (DOE 2018). The market is evolving quickly and prices are expected to decline.

A forward-looking optimistic battery storage scenario, Table 5, shows simple payback periods (SPP) of as low as 3.6 years under the high rate case and as high as 17 years under the low rate case. This assumes $\$ 250 / \mathrm{kWh}$ installed cost with no ongoing operational costs or degradation. ${ }^{5}$ Practical constraints related to capital budgets or desired SPP are likely to influence actual system designs, tending to prefer those with lower first costs and short payback.

Table 5. Battery storage system cost, savings, and simple payback period, relative to ASHP heating case.

\begin{tabular}{|c|c|c|c|c|c|c|c|c|c|}
\hline & \multicolumn{3}{|c|}{ Battery Storage } & \multirow{2}{*}{\multicolumn{3}{|c|}{$\begin{array}{l}\text { Savings } \\
\$(000) / \mathbf{y r}\end{array}$}} & \multirow{2}{*}{\multicolumn{3}{|c|}{$\begin{array}{c}\text { SPP } \\
\text { (years) }\end{array}$}} \\
\hline & \multicolumn{2}{|c|}{ Cap. } & \multirow{2}{*}{$\begin{array}{l}\text { Inst. } \\
\$(000)\end{array}$} & & & & & & \\
\hline & $\mathbf{k W}$ & kWh & & H & M & $\mathbf{L}$ & $\mathbf{H}$ & $\mathbf{M}$ & $\mathbf{L}$ \\
\hline Office & 108 & 430 & 108 & 30 & 15 & 7 & 3.6 & 7.3 & 15 \\
\hline Retail & 76 & 310 & 78 & 19 & 9 & 4 & 4.1 & 8.7 & 17 \\
\hline School & 834 & 3340 & 835 & 228 & 111 & 56 & 3.7 & 7.5 & 15 \\
\hline Note: 1 & $\begin{array}{l}\text { Elec. I } \\
\text { Assum }\end{array}$ & $\begin{array}{l}\operatorname{man} \\
\text { stor }\end{array}$ & $\begin{array}{l}\text { I } \$ 4 \\
\text { inst }\end{array}$ & $\begin{array}{l}\text { er k } \\
\text { d co }\end{array}$ & $\begin{array}{l}\text { p), } 1 \\
\text { of } 5\end{array}$ & & $\begin{array}{l}\text { L }( \\
\text { Vh. }\end{array}$ & & \\
\hline
\end{tabular}

While not a focus of this study, future work should consider the lifecycle cost tradeoffs of commercial ASHP. Since the market adoption of ASHP in commercial

\footnotetext{
${ }^{5}$ In practice, battery capacity decreases over time due to cycling and temperature-related aging. Components would likely
}

buildings in New England has been modest to date, more data are required to accurately characterize real-world average cost and lifecycle and performance. Results from this study could complement such lifecycle assessments.

\section{Conclusion}

Space heat electrification has the potential to be an important component of GHG reduction policy. Airsource heat pumps, in particular, offer a compelling path for strategic electrification for commercial buildings, with modest impacts on overall customer utility bills.

In Massachusetts, switching in 2019 from natural gas heat to an efficient ASHP could:

- Reduce space heating-related carbon emissions by up to $44 \%$

- Increase winter peak loads by a factor of 2 or more (on par with summer peaks)

- Increase total site energy costs by $4-18 \%$ (high demand rate) or decrease them by $5-7 \%$ (low)

- Increase heating-related energy costs by $55-130 \%$ (high demand rate), $17-55 \%$ (med), or decrease them by $12-40 \%$ (low).

Supplemental battery storage systems that are operated to minimize peak loads and sized to meet $50 \%$ of peak load for four hours could:

- Offset most or all of the winter peak increase while reducing peak load year-round

- Reduce total site energy costs relative to the heatpump case by 20 to $29 \%$ (high demand rate) and 13 to $20 \%$ (low)

- Increase annual site $\mathrm{kWh}$ usage by about $2 \%$

- Simple payback in 4-17+ years depending on installed costs and electric demand rates

Carbon reductions vary linearly with the ratio of carbon intensities of the grid to that of the baseline heating fuel.

Impacts on customer utility bills are highly sensitive to rates. Lower electric rates and higher heating fuel costs make ASHP more favorable on their own. Rates with high demand charges make battery storage systems more favorable.

Recommended topics for further study include:

1. Field measurement of real-world energy and capacity performance of commercial building ASHP vs. outdoor temperature and loading

2. GHG impact analysis based on scenarios with time-variable grid carbon intensity

3. Incremental and lifecycle cost analysis of using ASHP for new construction, major renovation, and retrofit replacement cases

4. Consider other energy storage system sizing options, control strategies, and cost models

5. Evaluate future energy rate structures to reflect scenarios with high adoption of renewables require a major overhaul or replacement approximately every ten years. 


\section{Acknowledgement}

The authors would like to thank the Massachusetts Clean Energy Center for supporting this effort, particularly Josh Kessler, Peter McPhee, and Meg Howard. We also thank Aldis Elfarsdóttir for preparing the baseline simulations.

\section{References}

DOE. (2012). New Construction Commercial Reference Building Models. U.S. Department of Energy. https://www.energy.gov/eere/buildings/newconstruction-commercial-reference-buildings

DOE. (2018). U.S. Battery Storage Market Trends. U.S. Department of Energy. May.

EIA. (2016). 2012 Commercial Buildings Energy Consumption Survey (CBECS). U.S. Energy Information Administration.

EIA. (2016). Carbon Dioxide Coefficients. U.S. Energy Information Administration.

EIA. (2018). Massachusetts Price of Natural Gas Sold to Commercial Consumers. U.S. Energy Information Administration.

https://www.eia.gov/dnav/ng/hist/n3020ma3m.htm

EIA. (2018). United States Electricity Profile 2016. U.S. Energy Information Administration.

Korn, D., J. Walczyk, A. Jackson, A. Machado, J. Kongoletos, and E. Pfann. (2016). Ductless Mini-Split Heat Pump Impact Evaluation. Cadmus Report to the Electric and Gas Program Administrators of Massachusetts and Rhode Island. Dec.

MassCEC and MassDOER. (2016). STATE OF CHARGE: Massachusetts Energy Storage Initiative Study. Massachusetts Clean Energy Center and Massachusetts Department of Energy Resources.
NEEP. (2017). Northeastern Regional Assessment of Strategic Electrification. Synapse Energy Economics and Meister Consulting Group Report to Northeast Energy Efficiency Partnerships. Jul.

NEEP. (2018). Cold Climate Air Source Heat Pump Specification and Product List. Northeast Energy Efficiency Partnership. Jun. https://neep.org/ashp/

OECD. (2015). Compare your country: CO2 from electricity generation. http://www.compareyourcountry.org/climate-policies

RMI. Billimoria, S., M. Henchen, L. Guccione, and L. Louis-Prescott. (2018). The Economics of Electrifying Buildings: How Electric Space and Water Heating Supports Decarbonization of Residential Buildings. Rocky Mountain Institute.

Schivley, G., I. Azvedo, and C. Samaras. (2018). Accessing the evolution of power sector carbon intensity in the United States. Environmental Research Letters. 13 (6)

Schuetter, S. and S. Hackel. (2015). Application of air source variable refrigerant flow in cold climates. Seventhwave.

Tarrojaa, B., F. Chiang, A. AghaKouchaka, S. Samuelsen, S.V. Raghavane, M. Weid, K. Sund, and T. Hong. (2018). Translating climate change and heating system electrification impacts on building energy use to future greenhouse gas emissions and electric grid capacity requirements in California. Applied Energy. vol. 225, pp. 522-534.

Walczyk, J. (2017). Evaluation of Cold Climate Heat Pumps in Vermont. Cadmus Report to the Vermont Public Service Department. Nov. 